\title{
Contribuições para o desenvolvimento nos municípios do Tocantins: com ou sem usinas hidrelétricas?
}

Comumente a implementação de projetos desenvolvimentistas são propagados como uma forma de promover o desenvolvimento local e a melhoria da qualidade de vida da população da região, com promessas de alavancamento de índices que elevam o patamar de desenvolvimento dos municípios envolvidos no projeto. Rotineiramente, a ideia desses projetos é formulada e discutida entre os membros governamentais e empresariais, e seguem uma tendência global de desenvolvimento. Sobretudo, no Tocantins, estado do norte brasileiro, com pouco mais de 30 anos de emancipação, essas obras foram intensificadas com a justificativa da inserção da região no patamar de desenvolvimento almejado para o País, contribuindo com a infraestrutura necessária e multimodal, para atender as demandas nacionais, com a premissa do desenvolvimento local. Esses planos de desenvolvimento buscam implementar desde rodovias, ferrovias, hidrovias, como também as Usinas Hidrelétricas de Energia (UHE), priorizadas principalmente nas duas últimas décadas. Assim, fazendo um recorte entre esses projetos desenvolvimentistas, hidrovias, como também as Usinas Hidrelétricas de Energia (UHE), priorizadas principalmente nas duas últimas décadas. Assim, fazendo um recorte entre esses projetos desenvolvimentistas, as Usinas Hidrelétricas de Energia (UHE's) foram em maior número dentro dos limites do estado do Tocantins, sendo que no período de 20 anos, foram construídas quatro UHE's: Lajeado,
Peixe Angical, São Salvador e Estreito, com planejamento para a instalação de mais quatro usinas (Ipueiras, Tupiratins, Serra Quebrada e Marabá). Diante deste cenário, buscou-se realizar uma análise contextualizada de indicadores econômicos, sociais e ambientais urbanos num período de 10 anos (2000-2010), em três municípios já impactados e que novamente serão impactados pela UHE de Ipueiras, buscando contribuir com o debate da viabilidade socioambiental da implementação ou não dessa UHE. Para tanto, utilizou-se a metodologia de análise documental de dados secundários onde foram escolhidos indicadores que retratam aspectos econômicos, sociais e ambientais urbanos para os anos de 2000 e 2010, com o objetivo de discutir se a implementação de UHE contribuiu ou não com o desenvolvimento local do município que sedia ou é implicado por tal empreendimento. Os resultados demonstraram que a implementação das UHE's não foram o fator determinante para a melhoria dos indicadores e apontam que as promessas de desenvolvimento para os municípios não foram alcançadas a partir desse empreendimento.

\section{Contributions to development in Tocantins municipalities: with or without hydroelectric plants?} \begin{abstract}
The implementation of developmental projects are commonly propagated as a way to promote local development and improve the quality of life of the population of the region, with
promises of leveraging indexes that increase the level of development of the municipalities involved in the project. Routinely, the idea of these projects is formulated and discussed among promises of leveraging indexes that increase the level of development of the municipalities involved in the project. Routinely, the idea of these projects is formulated and discussed among
government and business members, by following a global development trend. Above all, in Tocantins, a state in northern Brazil, with just over 30 years of emancipation, the implementation government and business members, by following a global development trend. Above all, in Tocantins, a state in northern Brazil, with just over 30 years of emancipation, the implementation
of these projects was intensified and was justified by the insertion of the region in the desired development level for the country, contributing with the necessary and multimodal infrastructure, to meet national demands, with the premise of local development. These development plans seek to implement highways, railways, waterways, as well as hydroelectric powe plants (HPPs), prioritized mainly in the last two decades. Thus, among these developmental projects, the Hydroelectric Power Plants were in greater number within the limits of the state of Tocantins, and during 20 years, four HPP's were built: Lajeado, Peixe Angical, São Salvador and Estreito, with planning for the installation of four more plants (Ipueiras, Tupiratins, Serra Quebrada and Marabá). In view of this scenario, the aim of this paper was to perform a contextualized analysis of economic, social and urban environmental indicators over a period of 10 years (2000-2010) in three municipalities already impacted and that will again be impacted by the Ipueiras HPP, seeking to contribute to the debate of the socio-environmental viability of environmenta aspe local development of the municipality that is hosts or is affected by such an undertaking. The results showed that the implementation of the HPP was not the determining factor for the improvement of the indicators, and revealed that the promises of development for the municipalities were not achieved from this project.
\end{abstract}

Keywords: Local development; Indicators; Hydroelectric projects; Socioenvironmental implications.

Topic: Planejamento, Gestão e Políticas Públicas Ambientais

Reviewed anonymously in the process of blind peer
Received: 03/02/2021

Approved: $27 / 02 / 2021$
Derval Gomes Ribeiro Neto (iD

Universidade Federal do Tocantins, Brasil http://lattes.cnpq.br/0793667599069011

http://orcid.org/0000-0003-1031-5009

derval@uft.edu.br

Patrícia Siqueira de Melo Rodrigues (iD) Universidade Federal do Tocantins, Brasil http://lattes.cnpq.br/8738628225543304 http://orcid.org/0000-0002-7155-3863 ptcsiqueira@gmail.com

\section{Ádila Maria Taveira de Lima (iD}

Universidade Federal do Tocantins, Brasil

http://lattes.cnpq.br/7969320948448461

http://orcid.org/0000-0002-0691-444X

adm.adila@gmail.com

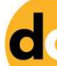

DOI: 10.6008/CBPC2179-6858.2021.002.0053
Carla Simone Seibert (D)

Universidade Federal do Tocantins, Brasi http://lattes.cnpq.br/6679543572745031

http://orcid.org/0000-0002-3988-7767

carlaseibert@yahoo.com

Lucimara Albieri de Oliveira (i)

Universidade Federal do Tocantins, Brasil

http://lattes.cnpq.br/8011223784204088

http://orcid.org/0000-0002-8890-8237

lucimaraalbieri@uft.edu.br

Referencing this:

RIBEIRO NETO, D. G.; RODRIGUES, P. S. M.; LIMA, A. M. T.; SEIBERT, C. S.; OLIVEIRA, L. A.. Contribuições para o desenvolvimento nos municípios do Tocantins: com ou sem usinas hidrelétricas?. Revista Ibero Americana de Ciências Ambientais, v.12, n.2, p.611-624, 2021. DOI: http://doi.org/10.6008/CBPC2179-6858.2021.002.0053 


\section{INTRODUÇÃO}

Os projetos nacionais de desenvolvimento e industrialização tiveram maior destaque a partir das três décadas que sucederam a Segunda Guerra Mundial (FURTADO, 1963; FONSECA, 2003). Dessa forma, após a segunda guerra mundial, surgiu ainda a classificação de "desenvolvimento" e "subdesenvolvimento" entendidos como descrição do estado de uma economia ou sociedade (LANG, 2016). A partir de então, dois terços da humanidade foram classificados como subdesenvolvidos, causando assim uma busca desenfreada para a tão sonhada classe dos "países desenvolvidos". Contudo, esse modelo foi conduzido à expropriação de territórios, patrimônio ambiental, história e cultura (SILVA et al., 2012).

O processo de transformação social, econômico, cultural e político são partes constituintes do desenvolvimento regional. Essas transformações são questões centrais para entender a dinâmica dos setores produtivos e a evolução de uma região (AJARRA et al., 1991; ABREU, 1994; OLIVEIRA, 2018). Borges et al. (2013) afirmam que para caracterizar de forma abrangente o desenvolvimento socioeconômico alcançado por um município ou região é necessário analisar variáveis que representem as dimensões econômicas, sociais, demográficas, de infraestrutura, dentre outras.

No Brasil, com a reestruturação do setor elétrico e o impulso em obras de infraestrutura para o desenvolvimento, especialmente a partir da década de 1990, culminou em grandes investimentos federais tanto na construção de usinas hidrelétricas, como empresas de comunicação, rodovias, ferrovias e outros (ABREU, 1994; CARVALHO et al., 1998). Estes investimentos fazem parte de uma estratégia política para o desenvolvimento socioeconômico brasileiro, onde são estabelecidos métodos destinados ao aprimoramento de infraestrutura básica, geração de emprego e à sustentação da economia (MALDANER et al., 2019). As políticas desenvolvimentistas ${ }^{1}$ têm um discurso de melhoria local, seja por meio dos empregos gerados ou pelo impulso na economia de um modo geral, que são alavancados pelo aumento da arrecadação de impostos e pelo pagamento da Compensação Financeiras pelo Uso de Recursos Hídricos (CFURH) (BRASIL, 2015).

No entanto, se verificarmos nas entrelinhas destes grandes empreendimentos, estarão interesses governamentais e de grupos empresariais e, no caso das hidrelétricas, se apoiam no discurso de energia "limpa" sob uma ótica "sustentável" de caráter inclusivo, sendo as empreiteiras as maiores interessadas em apoiar a manutenção deste modelo desenvolvimentista de construção de UHE's e rodovias (LITTLE, 2014; FAINGUELERNT, 2016; MALDANER et al., 2019; LIMA et al., 2019). Em outra face, análises apontam que os impactos advindos da implantação das UHEs prejudicam aspectos na escala local porque possuem magnitudes que causam desequilíbrio no meio ambiente e interferem no cotidiano da população e na estrutura econômica e social das cidades, impactando negativamente na distribuição de renda, migração, geração de emprego e lógica de atuação do mercado imobiliário (BATISTA, 2017).

Fonseca et al. (2013), dentre outros autores, consideram que houve uma retomada da matriz de

\footnotetext{
${ }^{1}$ Adotou-se o conceito de desenvolvimentismo desenvolvido por Furtado (1963), entendido como a busca do desenvolvimento por meio da ação ativa do Estado junto a sociedade civil organizada onde são criadas políticas públicas com o intuito de promover o desenvolvimento regional considerando suas especificidades como a localização geográfica, pressão populacional sobre os recursos naturais bem como a organização social e religiosa.
} 
políticas desenvolvimentistas (com uma nova roupagem) no governo Lula (2003-2010), sobretudo com a implementação do Programa de Aceleração do Crescimento (PAC), que representou importantes investimentos nesta fase, além da criação, em 2007, do Plano Decenal de Expansão de Energia 2026 (PDE 2026). No documento PDE 2026 a sociedade encontra informações sobre as indicações e perspectivas das futuras expansões do setor de energia em planejamento pelo governo até a ano de 2026. Expansões essas examinadas e elaboradas a partir da integração das diversas fontes de energia, gerando os seguintes resultados: análise da segurança energética do sistema; balanço de oferta e demanda de garantia física; disponibilidade de combustíveis, em particular do gás natural; cronograma dos estudos de inventário de novas bacias hidrográficas; e recursos e necessidades identificados pelo planejador para o atendimento à demanda (EPE, 2020).

Segundo Bortoleto (2001), os discursos otimistas de desenvolvimento e crescimento do Produto Interno Bruto (PIB) a partir da implementação de UHE's, contido no Plano Decenal de Expansão de Energia 2026 (PDE) minimizam os impactos negativos que geram perdas inestimáveis para o ambiente e para a sociedade local, pois provoca uma desestruturação das atividades pré-existentes, além de promover um crescimento populacional desordenado e perda da biodiversidade.

Além disso, muitos trabalhos evidenciam que o aumento do PIB vinculado às construções de UHE's não favorecem a região onde foi instalada, e que empreendimentos como estes não devem ser considerados como projetos de desenvolvimento local, onde os impactos gerados sobre a vida das pessoas quase nunca são devidamente mensurados e reparados (VAINER et al., 1992; BORTOLETO, 2001; LITTLE, 2014; CASTRO et al., 2015; FAINGUELERNT, 2016; GOMES et al., 2017; MALDANER et al., 2019; LIMA et al., 2019).

O PDE 2026 foi criado em decorrência do aumento na demanda energética brasileira, quando o governo esperava atrair investimentos de aproximadamente $\mathrm{R} \$ 1,4$ trilhões até o ano de 2026, o que correspondia mais da metade do PIB na época (EPE, 2020). Algumas obras milionárias no setor de energia hidrelétrica começaram neste mesmo período, com destaque para a construção de duas Usinas Hidrelétricas (UHE's) no Rio Madeira, em Rondônia, algo que causou muita polêmica na época após a rejeição da licença ambiental prévia pelo Instituto Brasileiro do Meio Ambiente e dos Recursos Naturais Renováveis (IBAMA), o que alimentou polêmicas em torno dos processos de licenciamentos ambientais no contexto do novo desenvolvimentismo (GONÇALVES, 2012).

Contudo, no estado do Tocantins, desde a sua emancipação em 1988, muitas políticas públicas foram implementadas e outras que já estavam no projeto de desenvolvimento do norte do país foram executadas, como a construção de quatro usinas hidrelétricas: Peixe Angical, São Salvador, Luiz Eduardo Magalhães e Estreito (LIMA et al., 2015). Há, ainda, projetos para instalação de mais quatro usinas no estado: Ipueiras, Tupiratins, Serra Quebrada e Marabá. Destaca-se que o projeto de Ipueiras foi embargado, sendo que as demais estão em diferentes fases de estudo e licenciamento (LIMA et al., 2015).

Os municípios de Peixe (sede da UHE Peixe Angical) e Miracema/Lajeado (UHE Luiz Eduardo Magalhães) sofreram grandes implicações socioambientais por sediarem a construção de suas respectivas UHE's, causando consequências também em municípios vizinhos, a exemplo de Ipueiras, que teve impactos 
decorrentes principalmente da área alagada em decorrência da construção da UHE Lajeado (LIMA, 2020). Ressalta-se que Ipueiras vem sendo alvo de tentativas para sediar a implementação de uma UHE, sendo relevante a inclusão desse município nesse estudo em um momento anterior à possível implementação. Portanto, considerando a análise dos municípios que já sediam um empreendimento hidrelétrico, é possível afirmar que a construção da UHE Ipueiras promoverá melhorias sociais e ambientais neste município? A análise contextualizada de alguns indicadores pode ser uma possibilidade para responder tal questionamento. Assim, este trabalho teve como objetivo estudar de maneira exploratória a evolução dos indicadores econômicos, sociais e ambientais urbanos de municípios que estão às margens do Rio Tocantins, que possuem empreendimentos hidrelétricos instalados, impactados por eles, e ainda com possibilidade de novas instalações, visando aprofundar as discussões acerca das repercussões socioambientais envolvendo a implantação de UHE'S e contribuir com análises para tomada de decisão nos municípios elencados.

\section{METODOLOGIA}

O estudo de caso abrange três municípios de pequeno porte, Lajeado, Peixe e Ipueiras, no estado do Tocantins, todos localizados às margens do Tocantins. Estes municípios vêm sofrendo transformações de ordem econômica, social, cultural e ambiental advindas dos projetos de desenvolvimento implementados na região. Destaca-se ainda que o estado teve cerca de 20 municípios atingidos por hidrelétricas, e que vem sofrendo impactos em grande escala. Portanto, a escolha dos municípios se deu pelo fato de estarem às margens do Rio Tocantins, serem sede de UHE e no caso de Ipueiras, por ter previsão de ser sede de uma futura UHE tendo já sofrido impacto da usina de Lajeado.

No caso de Lajeado, a implantação da UHE Luís Eduardo Magalhães (UHE Lajeado) ocorreu entre o final da década de 1990 e início dos anos 2000. O município de Peixe recebeu a UHE Peixe Angical no início dos anos 2000. Já Ipueiras foi impactado pela UHE Lajeado e terá, muito provavelmente, a implantação da UHE-Ipueiras, a qual foi suspensa em setembro de 2004 devido a não aprovação do EIA-RIMA e, atualmente, sua implantação vem sendo bastante discutida e até anunciada pelo governo estadual, segundo noticiado pela Secretaria de Comunicação do Estado do Tocantins, gerando tensões sociais na região.

Para averiguar o desenvolvimento de uma região, usualmente são utilizados indicadores socioeconômicos, instrumentos físicos, que tem como função demonstrar o desenvolvimento através de sinais ou indícios, auxiliando na leitura, descrição e avaliação de diferentes situações (BATISTA, 2017). Estes instrumentos também possibilitam uma análise mais abrangente do progresso de desenvolvimento de uma região, tendo como finalidade auxiliar na elaboração, implementação, monitoramento e avaliação de políticas públicas, sendo possível observar a sua evolução ao longo dos anos, bem como, as condições econômicas, sociais, ambientais, dentre outros (DOWBOR, 2008; OLIVEIRA, 2012). Estes indicadores são ferramentas importantes para entender as contribuições e impactos gerados pela construção de UHE's, na região, sejam eles negativos ou positivos.

O trabalho faz uma análise documental de dados secundários (MOREIRA, 2005) dos três municípios, obtidos do Instituto Brasileiro de Geografia e Estatística (IBGE) e da Secretaria de Planejamento do Estado 
do Tocantins (SEPLAN). Foram escolhidos indicadores que retratam aspectos econômicos, sociais e ambientais urbanos para os anos de 2000 e 2010, executando-se o cálculo de porcentagem da evolução de tais indicadores neste período, que estão demonstrados em tabelas ao longo das discussões.

Este período capta um momento de transição, o qual foi considerado nas análises, pois no ano de 2000 a UHE de Lajeado estava em fase de construção e iniciou sua operação em dezembro de 2001, e a UHE de Peixe ainda não existia, vindo a ser iniciada em 2002 com início de operação em 2006. Infelizmente, a não ocorrência do censo do IBGE de 2020 inviabilizou a inserção de dados mais atuais, devendo ser incorporados quando possível em trabalhos futuros.

Primeiramente, foram analisados os dados demográficos quanto ao incremento populacional total, urbano e rural correlacionando-o com o PIB e com a dinâmica econômica do município, com apoio do indicador sobre valores por setor de atividade. Para determinar os indicadores de emprego foi utilizado o saldo de empregos que consiste na diferença entre postos de trabalhos perdido e postos gerados, no mesmo período. Com esta média é possível indicar qual a contribuição da UHE nos empregos gerados e se estes permanecem contribuindo com a geração de renda local.

Os indicadores sociais abrangem a qualidade de vida quanto ao acesso a diferentes serviços, bens e oportunidades. Foram escolhidos o Índice de Desenvolvimento Humano Municipal (IDHM) e o índice de GINI. O primeiro retrata aspectos relacionados à renda, educação e expectativa de vida, variando entre 0 e 1 , sendo os valores mais próximo de zero os de pior situação. O segundo mensura o grau de concentração de renda, isto é, o nível de desigualdade social, variando também de 0 a 1, porém o zero corresponde a uma completa igualdade social (situação ideal), e o um, à desigualdade máxima.

Os indicadores ambientais urbanos escolhidos foram pertinentes ao saneamento, pois se relacionam direta ou indiretamente aos aspectos sociais, de saúde e preservação ambiental, isto é, à qualidade de vida, dignidade humana, bem-estar da população e proteção do meio ambiente. Além das reconhecidas repercussões na degradação e poluição ambiental, Oliveira (2014) menciona que a falta de saneamento impossibilita as pessoas de exercerem seus valores sociais, pois as condições sanitárias provocam privações de liberdades que vão desde as mais básicas, como se locomover nas ruas, até ter uma boa saúde. Portanto, tratou-se neste trabalho dos indicadores sobre abastecimento de água, banheiros por domicílio, esgotamento sanitário e destino do lixo.

\section{RESULTADOS E DISCUSSÃO}

O município de Lajeado fica localizado a $52 \mathrm{Km}$ da capital Palmas e seu acesso se dá pela rodovia TO010. A região fazia parte do município de Tocantínia e foi emancipado no ano de 1991, após dois anos da criação do estado do Tocantins. Contudo, sua ocupação e povoamento ocorreu muito tempo antes (século XIX) devido a sua localização às margens do Rio Tocantins, que naquela época o meio de transporte mais viável para a comercialização das mercadorias trazidas das regiões norte e nordeste era a navegação por botes e canoas. Com a descoberta do ouro em 1920, a região passou a abrigar garimpeiros de várias regiões, o que contribuiu decisivamente para o desenvolvimento do comércio e principalmente para o povoamento 
do local (OLIVEIRA, 2018). A partir da emancipação geopolítica, o município passou por várias transformações, principalmente na área econômica, com a construção da UHE de Lajeado iniciada em 1998 e concluída em 2002 (SEPLAN-TO, 2017). Com a conclusão da obra, $630 \mathrm{~km}^{2}$ do território foi alagado (LIMA et al., 2019) pelo represamento do Rio Tocantins, com profundidade média de 8 metros que banha seis municípios: Palmas, Porto Nacional, Lajeado, Miracema, Brejinho de Nazaré e Ipueiras (SEPLAN-TO, 2017).

O município de Peixe foi emancipado em 1985 e está localizado na região do médio Rio Tocantins, distante a 290 km da capital Palmas, e seu principal acesso ocorre através da rodovia BR-242 que liga o estado da Bahia ao Mato Grosso. Por não possuir pavimentação asfáltica em toda sua dimensão, a rodovia é utilizada primordialmente apenas como ligação à BR-153 (transbrasiliana), principal rodovia que liga o norte ao sul do país, ocorrendo a interseção no município de Gurupi. A origem do município está fortemente ligada ao garimpo do ouro da região de Natividade quando houve constantes conflitos entre garimpeiros e indígenas à época (PIMENTEL et al., 2011; COSTA-SANTOS et al., 2017). O Rio Tocantins era o principal meio de acesso às áreas de garimpo existentes na região. A construção da UHE de Peixe Angical, no município de Peixe, foi iniciada em 2002 e ficou interrompida por cerca de um ano até ser retomada em outubro de 2003, sendo finalizada em 2006 (SEPLAN-TO, 2017), formando um reservatório de 294 km² entre os municípios de Peixe, São Salvador do Tocantins e Paranã (LIMA et al., 2019).

Já o município de Ipueiras está localizado a 124 km da capital Palmas e seu acesso rodoviário se dá por meio das rodovias TO-458 e TO-365. A primeira liga o município de Ipueiras à BR-010, que permite acesso à capital estadual e à capital federal, enquanto a segunda conecta Ipueiras à BR-153. Quando ainda na condição de distrito, Ipueiras localizava-se em uma região de alagamento tendo sofrido uma enchente de grandes proporções na década de 1980, que forçou a população local a migrar para uma região mais alta a montante do Rio Tocantins (THEMAG, 1996). No ano de 1995 o distrito foi elevado à categoria de município, sendo pertencente à mesorregião de Porto Nacional (SEPLAN-TO, 2017). No ano 2000 iniciou-se estudos de viabilidade para a implantação da UHE em Ipueiras (ARAÚJO, 2003), porém em 2004 o EIA/RIMA não foi aprovado pelo órgão licenciador por inviabilidade ambiental. Alguns dos motivos da negação do empreendimento se referem ao alagamento de área de grande importância do cerrado $\left(1.066 \mathrm{Km}^{2}\right)$, atingindo locais de preservação, e relação desfavorável de potência de energia/área alagada, concluindo que os impactos seriam irreversíveis e de grande monta para a região (ARAÚJO, 2003; IBAMA, 2003; PINHEIROS, 2007; ANDRADE, 2017).

Quanto aos dados populacionais, os três municípios apresentaram um aumento demográfico e de urbanização (Tabela 1), seguindo uma tendência estadual, visto que o movimento de interiorização brasileiro foi fortalecido pela emancipação recente do estado do Tocantins. Observa-se que mesmo aqueles municípios que são sede de empreendimentos hidrelétricos, como é o caso de Lajeado e Peixe, a população tem um índice próximo à média de crescimento dos demais municípios do Tocantins, isso porque mesmo com a implementação da UHE, a população que é atraída para o local é uma população flutuante, apenas enquanto ocorre a construção do empreendimento e afeta o contingente populacional de maneira significativa neste período (MALDANER et al., 2019). 
Tabela 1: Evolução da população e produto interno bruto (PIB) no período de 2000 a 2010.

\begin{tabular}{|c|c|c|c|c|c|c|c|c|c|c|c|}
\hline & \multicolumn{3}{|c|}{ Lajeado } & \multicolumn{3}{|l|}{ Peixe } & \multicolumn{3}{|c|}{ Ipueiras } & \multirow{2}{*}{\begin{tabular}{|l|} 
TO \\
$\%$ \\
\end{tabular}} & \multirow{2}{*}{\begin{tabular}{|l|} 
BR \\
$\%$ \\
\end{tabular}} \\
\hline & 2000 & 2010 & $\%$ & 2000 & 2010 & $\%$ & 2000 & 2010 & $\%$ & & \\
\hline População & 2.344 & 2.773 & 18,30 & 8.763 & 10.384 & 18,50 & 1.166 & 1.639 & 40,50 & 19,50 & 12,30 \\
\hline População Urbana & 1.583 & 2.166 & 36,80 & 3.672 & 5.235 & 42,50 & 586 & 958 & 63,40 & 26,70 & 16,70 \\
\hline População Rural & 761 & 607 & $-20,20$ & 5.091 & 5.149 & 1,10 & 580 & 681 & 17,40 & $-1,20$ & $-6,50$ \\
\hline PIB per capita $(R \$)^{*}$ & 2.449 & 607 & $-75,21$ & 1.838 & 40.609 & $2.109,41$ & 2.595 & 9.478 & 265,24 & $\mathrm{NI}{ }^{* *}$ & 27,36 \\
\hline
\end{tabular}

* IBGE, 2019; **NI - Não Identificado.

Fonte: SEPLAN (2017); IBGE (2007); IBGE (2010).

O incremento populacional de Ipueiras entre os anos de 2000 e 2010 foi bem acima da média, e em 2010 este município apresentava um PIB per capita semelhante de Lajeado, tendo acrescido seu valor em 2010, enquanto Lajeado teve decréscimo (Tabela 01). Observa-se que não há uma correlação direta entre crescimento populacional e PIB, e os dados contradizem o protagonismo da UHE no tocante ao incremento populacional e aumento do PIB. Maldaner et al. (2019) afirmam que apesar de ter havido um aumento gradativo do PIB em alguns municípios impactados pelas UHE's, não se pode atribuir esse resultado apenas à sua implantação, porque existem outros fatores que impulsionam esse indicador. Os autores também apontam períodos de queda do PIB em municípios impactados por UHE's, demonstrando que as usinas alavancam seu valor sobretudo no período de sua construção, mas não de sua operação.

Peixe, que é sede da UHE Peixe Angical, teve um aumento exponencial do PIB per capita entre 2000 e 2010 e o maior valor dentre os três municípios especificamente em 2010. Destaca-se o período de implantação da Usina de Peixe entre 2002 e 2006, enquanto em Lajeado foi de 1998 e 2002. Portanto, os dados de 2000 foram colhidos antes do início de implantação da Usina de Peixe e durante a construção da Usina em Lajeado. Deve-se monitorar a permanência ou não do alto valor do PIB ao longo dos próximos anos em Peixe, observando-se que o PIB per capita de Lajeado não se sustentou após findada a construção da UHE. Segundo Lima et al. (2019) as UHE's de Peixe Angical e Lajeado contribuíram com a arrecadação de ICMS nos municípios sede do empreendimento, mas estes empreendimentos não foram determinantes para o desenvolvimento local, uma vez que os municípios que não apresentam implantação de hidrelétricas também obtiveram melhora nos índices econômicos, como apontado em Ipueiras, demonstrando ser esta uma tendência em todo o Estado. Tundisi et al. (2006) também relatou que, com a criação do Estado no final da década de 80 e com a construção da capital, a região situada do lado direito do rio passou a apresentar atrativos para o seu desenvolvimento, incentivando a vinda de trabalhadores de várias partes do país para esses municípios, o que contribuiu para o aumento da população e do PIB dessa região.

Sobre a relação entre população rural e urbana, todos os municípios incrementaram sua população urbana, seguindo uma tendência brasileira e por conseguinte, tocantinense. Ipueiras foi o único município com aumento expressivo da população rural, contrariando a tendência dos demais e da média estadual e nacional (Tabela 1). O resultado observado para Ipueiras, a ser investigado com maior profundidade em trabalhos futuros, pode ter relação com o incentivo na produção agrícola, especialmente na agricultura familiar e produções de pequeno porte e, talvez por Ipueiras não ter sido sede de empreendimento hidrelétrico, por isso não provocou uma alteração na dinâmica econômica urbana como usualmente ocorre e, consequentemente, não estimulou a população rural a migrar para a cidade em busca de emprego. 
O trabalho de Fornaro (2012) demonstra que houve aumento da área de plantio para todo o estado, havendo um grande incremento no município de Ipueiras, que não possuía produção de soja em 1999, mas chegou a produzir mais de 10 mil toneladas desse grão em 2009; isso pode justificar o aumento do PIB, mas não a manutenção da população rural, tendo em vista que é uma produção de latifúndio. $O$ fator cultural de município interiorano e população mais velha favorece também a manutenção das pessoas na área rural, porém os outros municípios também advêm de povoados mais antigos. Portanto, esta questão carece de investigação e de aporte em outras fontes de dados.

Quando analisados os indicadores por setor de atividades, nota-se a importância da agropecuária para Peixe, e como tal setor é incrementado em Ipueiras. A indústria também tem uma evolução positiva nos três municípios, com destaque para Peixe que deu um salto surpreendente entre 2000 e 2010 (Tabela 2). 0 setor de serviços também foi impulsionado nos três municípios, indicando uma adaptação no contexto de reordenamento e desenvolvimento da rede urbana do Tocantins.

Tabela 2: Evolução do valor adicional bruto a preços correntes por setor de atividade dos municípios de Lajeado, Peixe e Ipueiras no período de 2000 a 2010.

\begin{tabular}{|l|l|l|l|l|l|l|l|l|l|}
\cline { 2 - 10 } \multicolumn{1}{c|}{} & Lajeado & \multicolumn{3}{l|}{ Peixe } & \multicolumn{2}{l|}{ lpueiras } \\
\cline { 2 - 11 } \multicolumn{1}{c|}{} & $\mathbf{2 0 0 0}$ & $\mathbf{2 0 1 0}$ & $\mathbf{\%}$ & $\mathbf{2 0 0 0}$ & $\mathbf{2 0 1 0}$ & $\mathbf{\%}$ & $\mathbf{2 0 0 0}$ & $\mathbf{2 0 1 0}$ & $\mathbf{\%}$ \\
\hline Agropecuária & 479,00 & 842,10 & 75,80 & $11.875,00$ & $30.464,78$ & 156,50 & $1.298,00$ & $5.444,60$ & 319,40 \\
\hline Indústria & $1.619,00$ & $6.999,88$ & 332,30 & 787,00 & $328.658,09$ & $41.660,80$ & 111,00 & 731,92 & 559,30 \\
\hline Serviços & $3.014,00$ & $18.709,38$ & 520,70 & $10.533,00$ & $55.255,30$ & 424,50 & $1.558,00$ & $8.740,97$ & 461,00 \\
\hline
\end{tabular}

Fonte: SEPLAN (2017).

O censo do IBGE passou a coletar dados sobre financiamento concedido a produtores e cooperativas em 2010, visando encaminhar políticas para o desenvolvimento do setor agropecuário. Em Lajeado foi registrado $\mathrm{R} \$ 1$ 19.700,00 de financiamento em agricultura e $\mathrm{R} \$ 487.500,00$ em pecuária. Peixe obteve $\mathrm{R} \$$ 3.375.155,00 em agricultura e R\$18.209.354,00 em pecuária. Em menor vulto, Ipueiras contou com R\$ 587.268,00 em agricultura e maior investimento em pecuária, na ordem de $\mathrm{R} \$ 1.004 .274,00$. Vale ressaltar que há notoriamente grande dificuldade de o pequeno produtor ter acesso à financiamentos devido à falta de conhecimento e de informação, assim como de garantias a serem oferecidas aos bancos para aprovar o financiamento (SEPLAN-TO, 2017).

O volume de financiamento na agricultura em Peixe pode ser um indicativo do alinhamento de sua produção com a ordem global, visto que geralmente os grandes latifundiários ou empresas multinacionais conseguem maiores quantias em investimentos no sistema financeiro para aplicar em suas propriedades. 0 cultivo de commodities despende de maior tecnologia e, consequentemente, de maior volume de dinheiro, do que a pecuária ou ainda, do que a agricultura familiar. Já em Lajeado e Ipueiras, os investimentos são voltados prioritariamente a pecuária, o qual ocorre geralmente com menor nível de mecanização e de volumes monetários. Porém, quando comparados esses dois últimos, Ipueiras recebeu um valor de financiamento significativamente maior para agricultura do que Lajeado. Vale ressaltar que grande parte do município de Lajeado se configura como terras indígenas, além da presença do Parque Estadual de Lajeado, o que reduz as dimensões territoriais para exploração agropecuária (SEPLAN-TO, 2012).

A implantação de UHEs é defendida também pela geração de emprego e oportunidades de pequenos 
negócios locais que a implementação do empreendimento proporciona, mas ao observar os dados de saldo de emprego nesses três municípios observa-se que nas cidades que são sede do empreendimento houve uma queda mais expressiva (Tabela 3).

Tabela 3: Saldo de empregos nos municípios de Lajeado, Peixe e Ipueiras em 2002 e 2010.

\begin{tabular}{|l|l|l|l|l|l|}
\hline Lajeado & Peixe & Ipueiras \\
\hline $\mathbf{2 0 0 2}$ & $\mathbf{2 0 1 0}$ & $\mathbf{2 0 0 2}$ & $\mathbf{2 0 1 0}$ & $\mathbf{2 0 0 2}$ & $\mathbf{2 0 1 0}$ \\
\hline-16 & -11 & 249 & -66 & 1 & -2 \\
\hline
\end{tabular}

Fonte: SEPLAN-TO (2019).

Observa-se claramente que, na ocasião da construção do empreendimento, há saldo de emprego positivo, no entanto, com a finalização da obra física, os empregos despencam, visto em Lajeado, que ao finalizar a obra em 2001, aparece um saldo negativo de empregos em 2002; em Peixe, onde a UHE foi finalizada em 2006, aparece saldo negativo ainda em 2010; e Ipueiras, houve uma queda de maneira mais suave, mas também demonstra que a UHE não gera emprego local. Isso corrobora com a afirmação de que sendo sede ou não do empreendimento, em nível local, para a geração de emprego e renda, não há contribuição positiva. Dessa forma, constata-se que após a finalização da construção, os empregos gerados não têm continuidade e não garantem a manutenção de emprego e renda e, consequentemente, o incremento da economia em nível local. Os pequenos negócios criados em função da obra perdem a clientela rapidamente e, assim, entram em declínio. O investimento em serviços de assistência básica, antes necessário para atendimento desses trabalhadores e famílias, muitas vezes não tem como ser mantido unicamente pelo poder municipal, comprometendo também a governança e manutenção dos serviços no local.

Quando avaliado os índices sociais verifica-se que os três municípios apresentaram melhora dos Índice de Desenvolvimento Humano Municipal (IDHM) no período analisado, passando da classificação de baixo para médio no valor geral não decomposto (Tabela 4). O IDHM Educação foi o que apresentou maior crescimento em todos os municípios e os demais apresentaram aumentos menos expressivos, porém seus valores ainda são classificados como baixos.

Tabela 4: Evolução dos índices socioeconômicos dos municípios de Lajeado, Peixe e Ipueiras no período de 2000 a 2010.

\begin{tabular}{|c|c|c|c|c|c|c|c|c|c|}
\hline & \multicolumn{3}{|c|}{ Lajeado } & \multicolumn{3}{|l|}{ Peixe } & \multicolumn{3}{|c|}{ Ipueiras } \\
\hline & 2000 & 2010 & $\%$ & 2000 & 2010 & $\%$ & 2000 & 2010 & $\%$ \\
\hline IDHM & 0,506 & 0,675 & 33,40 & 0,482 & 0,674 & 39,80 & 0,384 & 0,620 & 61,40 \\
\hline IDH-M Renda & 0,589 & 0,673 & 14,20 & 0,549 & 0,679 & 23,60 & 0,458 & 0,576 & 25,70 \\
\hline IDHM Educação & 0,331 & 0,573 & 73,10 & 0,285 & 0,555 & 94,70 & 0,187 & 0,518 & 177,00 \\
\hline IDHM Longevidade & 0,666 & 0,798 & 19,80 & 0,715 & 0,812 & 13,50 & 0,659 & 0,797 & 20,90 \\
\hline Índice de GINI & 0,503 & 0,597 & 18,60 & 0,540 & 0,635 & 17,50 & 0,558 & 0,431 & $-22,80$ \\
\hline
\end{tabular}

Fonte: SEPLAN (2017).

Contudo, era preconizado na ocasião da construção da UHE, que os municípios de Lajeado e Peixe tivessem maior evolução, sendo sede e tendo em vista os supostos melhoramentos sociais que a usina deveria proporcionar, mas isto se concretizou timidamente, sobretudo no aspecto da renda, na qual os resultados deveriam ser mais diretos e efetivos. Ipueiras é o município que apresenta os melhores avanços de índices dentre os três, tanto em sua média geral, como em suas médias decompostas referentes a renda, 
longevidade e, principalmente, educação, demonstrando que mesmo o município não recebendo o projeto hidrelétrico teve mais melhorias sociais que os que têm empreendimento de grande porte, com viés desenvolvimentista. Portanto, a implantação desse tipo de empreendimento não foi determinante para o desenvolvimento local, nem nas cidades que se instalam e nem nas regiões circunvizinhas, como é o caso de Ipueiras. Aliás, essa análise demonstra que Ipueiras está alcançando indicadores de melhoria sem a UHE instalada.

O município de Ipueiras também alcançou melhores resultados quanto à desigualdade social, perceptível pela queda do índice de GINI na ordem de 22,8\%, sendo o único a obter uma progressão negativa, o melhor resultado dentre os três municípios. Já tal indicador em Lajeado e Peixe teve seu valor aumentado demonstrando que o desequilíbrio social é acentuado e piorou no período analisado, o que demonstra que a existência da UHE não colaborou para trazer equilíbrio social, ao contrário, ela pode ter contribuído para acentuar as desigualdades (Tabela 04). Portanto, assim como o IDH, o índice de GINI revela que a existência da UHE não foi fundamental para melhorar os aspectos sociais nos municípios.

Alinhados a esta observação, Maldaner et al. (2019) afirmam que não se pode atribuir os resultados das melhorias sociais somente à implementação das UHE's, pois há uma ação de caráter institucional em função da emancipação do norte goiano que intensificou a participação do Estado, provendo bens e serviços nos municípios tocantinenses. De uma forma ou de outra, sem a participação da sociedade, qualquer plano de desenvolvimento pode ter seus resultados comprometidos, pois mesmo que haja uma grande impulsão de recursos ocasionada por uma política nacional, é necessário envolvimento da gestão local e da comunidade para a continuidade e manutenção das ações.

Para os índices de saneamento, a observação quanto aos melhores resultados em Ipueiras se repete. Há um aumento importante da rede de distribuição geral de água no município de Ipueiras $(264,7 \%)$ sendo um aumento muito significativo em relação aos municípios de Peixe $(60,8 \%)$ e Lajeado $(47,2 \%)$. Ipueiras também se destacou pelo aumento no número de domicílios particulares permanentes com banheiros de uso exclusivo, com 476,0\% de acréscimo (Tabela 5).

Tabela 5: Abastecimento de água e banheiros por domicílios nos municípios de Lajeado, Peixe e Ipueiras no período de 2000 a 2010.

\begin{tabular}{|c|c|c|c|c|c|c|c|c|c|}
\hline \multicolumn{10}{|c|}{ Saneamento básico - Domicílios Particulares Permanentes, por Forma de Abastecimento de Água } \\
\hline & \multicolumn{3}{|c|}{ Lajeado } & \multicolumn{3}{|l|}{ Peixe } & \multicolumn{3}{|c|}{ Ipueiras } \\
\hline & 2000 & 2010 & $\%$ & 2000 & 2010 & $\%$ & 2000 & 2010 & $\%$ \\
\hline Rede geral de distribuição & 371 & 546 & 47,20 & 1.215 & 1.945 & 60,80 & 99 & 361 & 264,70 \\
\hline Poço ou nascente na propriedade & 174 & 190 & 9,20 & 1.094 & 1.204 & 10,10 & 141 & 140 & $-0,70$ \\
\hline Outra & 17 & 65 & 282,40 & 48 & 140 & 194,70 & 31 & 17 & $-45,20$ \\
\hline Total $^{1}$ & 562 & 801 & 42,50 & 2.357 & 3.289 & 39,50 & 271 & 518 & 91,10 \\
\hline \multicolumn{10}{|c|}{ Domicílios Particulares Permanentes, por Existência e Número de Banheiros de Uso Exclusivo do Domicílio - 2000 e 2010} \\
\hline & 2000 & 2010 & $\%$ & 2000 & 2010 & $\%$ & 2000 & 2010 & $\%$ \\
\hline Tinham & 371 & 730 & 96,80 & 1.062 & 2.689 & 153,20 & 75 & 432 & 476,00 \\
\hline 1 & 311 & 599 & 92,60 & 883 & 2.227 & 152,20 & 69 & 373 & 440,60 \\
\hline 2 & 48 & 104 & 116,70 & 142 & 368 & 159,20 & 5 & 52 & 940,00 \\
\hline 3 & 7 & 25 & 257,10 & 26 & 75 & 188,50 & 0 & 3 & 300,00 \\
\hline 4 ou mais & 5 & 2 & $-60,00$ & 11 & 19 & 72,70 & 1 & 4 & 300,00 \\
\hline Não tinham & 191 & 71 & $-62,80$ & 1.295 & 600 & $-53,70$ & 196 & 86 & $-56,10$ \\
\hline Total $^{1}$ & 562 & 801 & 42,50 & 2.357 & 3.289 & 39,50 & 271 & 518 & 91,10 \\
\hline
\end{tabular}

Fonte: SEPLAN-TO (2017). 
De acordo com o IBGE, os três municípios não dispunham de rede de coleta e de estação de tratamento do esgoto sanitário no ano 2000, e em 2010 apenas o município de Peixe implantou a coleta com duas formas de tratamento da matéria esgotada (por lagoa aeróbica e facultativa) antes do lançamento no corpo d’água, mas não há registros oficiais disponíveis sobre a amplitude e qualidade do tratamento. Observa-se um aumento bem maior de fossas sépticas em Lajeado e Ipueiras devido à ausência de rede de coleta nestes municípios (Tabela 6). No que se refere ao destino do lixo, o município de Ipueiras também apresentou o maior aumento no índice de domicílios que tinha o serviço de coleta, chegando a 308,1\% de acréscimo, seguido de Peixe com $289,7 \%$ e Lajeado com apenas $102,3 \%$ de incremento de domicílios beneficiados com o serviço (Tabela 7).

Tabela 6: Presença de fossas sépticas (Particulares e Permanentes) nos municípios de Lajeado, Peixe e Ipueiras no período de 2000 e 2010.

\begin{tabular}{|l|l|l|l|l|l|l|l|}
\hline \multicolumn{2}{|l|}{ Lajeado } & Peixe & \multicolumn{2}{l|}{ Ipueiras } \\
\hline $\mathbf{2 0 0 0}$ & $\mathbf{2 0 1 0}$ & \% & $\mathbf{2 0 0 0}$ & $\mathbf{2 0 1 0}$ & \% & $\mathbf{2 0 0 0}$ & $\mathbf{2 0 1 0}$ \\
\hline 18 & 278 & $1.444,40$ & 150 & 391 & 160,70 & 3 & 416 \\
\hline
\end{tabular}

Fonte: SEPLAN (2017).

Tabela 7: Destino do Lixo nos municípios de Lajeado, Peixe e Ipueiras no período de 2000 a 2010.

\begin{tabular}{|c|c|c|c|c|c|c|c|c|c|}
\hline & \multicolumn{3}{|c|}{ Lajeado } & \multicolumn{3}{|l|}{ Peixe } & \multicolumn{3}{|c|}{ Ipueiras } \\
\hline & 2000 & 2010 & $\%$ & 2000 & 2010 & $\%$ & 2000 & 2010 & $\%$ \\
\hline Coletado & 314 & 632 & 102,30 & 428 & 1.668 & 289,70 & 87 & 355 & 308,10 \\
\hline $\begin{array}{l}\text { Diretamente } \\
\text { por serviço } \\
\text { de limpeza }\end{array}$ & 310 & 627 & 102,30 & 289 & 1.648 & 470,20 & 87 & 355 & 308,10 \\
\hline $\begin{array}{l}\text { Em caçamba } \\
\text { de serviço } \\
\text { de limpeza }\end{array}$ & 4 & 5 & 25,00 & 139 & 20 & $-85,60$ & - & - & - \\
\hline $\begin{array}{l}\text { Queimado } \\
\text { na } \\
\text { propriedade }\end{array}$ & 198 & 146 & $-26,30$ & 1.281 & 1.478 & 15,40 & 105 & 132 & 25,70 \\
\hline $\begin{array}{l}\text { Enterrado } \\
\text { na } \\
\text { Propriedade }\end{array}$ & 22 & 3 & $-86,40$ & 81 & 61 & $-24,70$ & 10 & 9 & $-10,00$ \\
\hline $\begin{array}{l}\text { Jogado em } \\
\text { terreno } \\
\text { baldio ou } \\
\text { logradouro }\end{array}$ & 27 & 20 & $-25,90$ & 555 & 76 & $-86,30$ & 69 & 22 & $-68,10$ \\
\hline $\begin{array}{l}\text { Jogado em } \\
\text { rio ou lago }\end{array}$ & - & - & - & - & - & - & - & - & - \\
\hline Outro & 1 & - & $-100,00$ & 12 & 6 & $-50,00$ & - & - & - \\
\hline
\end{tabular}

Fonte: SEPLAN-TO (2017).

Os indicadores ambientais urbanos analisados demonstram que houve evolução dos índices de saneamento nos três municípios, ressaltando que Ipueiras permanece à frente dos municípios de Lajeado e Peixe quando verificadas as variáveis rede de distribuição geral de água, domicílios com banheiros e destino do lixo. Em relação à rede de coleta de esgoto, apenas Peixe apresentou implantação. Ipueiras aumentou significativamente a quantidade de fossas sépticas, superando Lajeado.

Obter esses serviços são de grande importância para uma população, pois ter direito à água e saneamento implicam na realização de muitos outros direitos humanos como saúde, educação, oportunidades de trabalho, que são essenciais à vida e imprescindíveis para a erradicação da pobreza (ALBUQUERQUE, 2012), assim como para a conservação dos recursos naturais (TEIXEIRA et al., 2005; 
MENDONÇA et al., 2005) como manutenção dos mananciais, lençóis freáticos, solo e preservação da fauna e da flora (IHA, 2006; VERA et al., 2007).

\section{CONCLUSÕES}

Após averiguar a evolução dos dados socioeconômicos dos municípios de Lajeado, Peixe e Ipueiras, percebeu-se uma significativa independência do desenvolvimento local quanto a instalação das UHE's, pois o município de Ipueiras, o qual não é sede de UHE, apresentou aumento das variáveis econômicas, sociais e ambientais urbanas no período analisado, muitas vezes superando os outros dois municípios. Destaca-se ainda que isso ocorreu seguindo uma tendência regional e não necessariamente em decorrência da implementação de um novo empreendimento hidrelétrico.

As UHE's de Lajeado e Peixe Angical contribuíram para o aumento exponencial do PIB, no entanto os municípios apresentam pouca evolução do IDHM e piora do índice de GINI. Isto demonstra baixa implicação da presença das usinas na melhora da qualidade de vida da população, uma piora na distribuição de renda e um aumento da desigualdade social sugerindo que os benefícios gerados na economia são captados por um grupo social privilegiado, com pouca ou nenhuma relação com a escala local. O fato do PIB crescer substancialmente no período de implantação do empreendimento não implica em sua reversão em benefícios sociais ao longo dos anos, além disso, ainda que haja melhora na arrecadação, os impactos e conflitos ocasionados e deixados para serem sanados ao longo do tempo não são resolvidos e muitas vezes se estendem por longos períodos sem solução. Dessa forma, a implantação de um empreendimento hidrelétrico no município de Ipueiras, como previsto, poderá acarretar tensões e desvantagens socioeconômicas e ambientais para a população local frente aos dados obtidos, pois conforme demonstrado, o município vem apresentando respostas a seu processo de desenvolvimento na média dos demais municípios tocantinenses. Algumas dessas tensões podem ser identificadas através do embargo da implantação da UHE de Ipueiras pelo órgão licenciador, que além de impactar de forma negativa a vida das pessoas e causar inúmeros problemas ambientais, certamente não promoverá de maneira permanente e sustentável o desenvolvimento local.

O desenvolvimento local não pode ser exógeno, por meio de um projeto externo e impositivo, e sem o envolvimento da população e da gestão local desde a sua concepção. A implantação de um empreendimento da magnitude de uma usina hidrelétrica provoca uma desestruturação das atividades preexistentes e um desarranjo importante especificamente em sua fase de construção com reverberações posteriores, além dos amplos e significativos impactos ambientais muito discutidos. Diante dos resultados obtidos, a incorporação de mecanismos e ações para apoiar os rearranjos necessários na escala local demonstraram ser insuficientes para gerar resultados consistentes e positivos. Portanto, a implantação das UHEs não assegura, isoladamente, melhor distribuição de renda e aumento da qualidade de vida.

Assim, quando voltamos à questão inicial desse trabalho - se é possível afirmar que a construção da UHE Ipueiras promoverá melhorias sociais e ambientais neste município, baseada na contribuição no desenvolvimento local dos outros municípios que já possuem UHE - concluímos que não se pode atribuir as 
melhorias dos indicadores a instalação dessa obra desenvolvimentista. E se o título desse trabalho versa sobre 'com ou sem hidrelétrica', observou-se que para o município de Ipueiras pode causar mais tensões socioambientais e efeitos negativos do que positivos, como já observado em outros municípios, pois averiguou-se que Ipueiras, hoje sem hidrelétrica alcançou senão maiores, mas equivalentes indicadores de melhoria de desenvolvimento local que os outros municípios.

\section{REFERÊNCIAS}

ABREU, M. P.. A Ordem do progresso. Rio de Janeiro: Campus, 1994.

AJARRA, C.; FIGUEIREDO, A. H. F.; BEZERRA, V. M. d'A. C.; BARBOSA J. G.. O estado do Tocantins: reinterpretação de um espaço de fronteira. Revista Brasileira de Geografia, Rio de Janeiro, v.53, n.4, p.5-48, 1991.

ALBUQUERQUE, C.. Derechos hacia el final: buenas prácticas em la realización de los derechos al agua y al saneamiento. Lisboa: ONGAWA, 2012

ANDRADE, A. L.. A Viabilidade ambiental de usinas hidrelétricas e a aplicação da avaliação ambiental estratégica no Brasil. Tese (Doutorado em Planejamento Energético) - Universidade Federal do Rio de Janeiro, 2017.

ARAÚJO, R. M.. Uma retrospectiva da expansão do sistema elétrico na bacia do rio Tocantins, com estudo de caso na região de Lajeado - Palmas - Porto Nacional, TO, 1996-2003. Dissertação (Mestrado) - Universidade Estadual de Campinas, Campinas, 2003.

BRASIL. Ministério de Minas e Energia. Plano Decenal de Expansão de Energia 2024. Brasília: Ministério de Minas e Energia, 2015.

BATISTA, N. C.. O impacto do "Desenvolvimento": A Usina Luís Eduardo Magalhães e a organização socioespacial e econômica das cidades diretamente afetadas. Brasília, 2017.

BORGES, C. M.; SANTOS, M. J.; VIEIRA, E. T.. Tocantins: O Crescimento e o Desenvolvimento Econômico Regional com a Criação do novo Estado. Revista Gestão \& Regionalidade, v.29, n.85, 2013.

BORTOLETO, E. M.. A implantação de grandes hidrelétricas: desenvolvimento, discurso e impactos. Geografares, n.2, p.53-62, 2001.

CARVALHO, J. O.. Revisão das estratégias de desenvolvimento do Centro-oeste: relatório final da coordenação. In: PROJETO DE COOPERAÇÃO TÉCNICA PARA O PLANEJAMENTO DO DESENVOLVIMENTO REGIONAL BRASILEIRO. MPO/SEPRE/IICA. Anais. Brasília, 1998.

CASTRO, F.; HOGENBOOM, B.; BAUD, M.. Governança ambiental na América Latina. Ciudad Autónoma de Buenos Aires: CLACSO; Amsterdã: Engov, 2015.

COSTA-SANTOS, L. A.; BATISTA, A. C.; NEVES, C. O. M.; CARVALHO, E. V.; SANTOS, M. M.; GIONGO, M.. Análise multitemporal do uso e cobertura da terra em nove municípios do Sul do Tocantins, utilizando imagens Landsat. Agro@mbiente, v.11, p.111-118, 2017.
DOWBOR, L.. Indicadores: afinal, o que estamos medindo?. Democracia Econômica. Vozes, 2008

EPE. Empresa de Pesquisa Energética. Plano Decenal de Expansão de Energia 2026 (PDE 2026). EPE, 2020.

FAINGUELERNT, M. B.. A trajetória histórica do processo de licenciamento ambiental da usina hidrelétrica de Belo Monte. Ambiente e Sociedade, São Paulo, v.19, n.2, p.245264, 2016.

FONSECA, P. C. D.. Sobre a intencionalidade da política industrializante no Brasil na década de 1930. Revista de economia política, São Paulo, n.89, p.133-148, 2003.

FONSECA, P. C. D.; CUNHA, A. M.; BICHARA, J. S.. O Brasil na Era Lula: retorno ao desenvolvimentismo?. Nova Economia, v.23, n.2, 2013

FORNARO, A. C.. Logística e agronegócio globalizado no estado do Tocantins: um estudo sobre a expansão das fronteiras agrícolas modernas no território brasileiro. Dissertação (Mestrado) - Universidade Estadual de Campinas, Campinas, 2012.

FURTADO, C.. Desenvolvimento e subdesenvolvimento. Fundo de Cultura, 1963.

GOMES, C. S.; ROQUETTI, D. R.; PULICE, S. M. P.; MORETTO, E. M.. Usinas Hidrelétricas e o Desenvolvimento Municipal: o Caso das Usinas Hidrelétricas do Complexo PelotasUruguai. Gestão Ambiental e Sustentabilidade, v.6, n.2, 2017.

GONÇALVES, R.. Novo desenvolvimentismo e liberalismo enraizado. Serviço Social e Sociedade, São Paulo, n.112, 2012. DOI: https://doi.org/10.1590/S010166282012000400003

IBAMA. Instituto Brasileiro do Meio Ambiente e dos Recursos Naturais Renováveis. Processo: 02001.000310/2003-09. Licenciamento Ambiental para a UHE Ipueiras. IBAMA, 2003.

IBGE. Instituto Brasileiro de Geografia e Estatística. Censos Demográficos, Econômicos e Agropecuários. Anos: 1980 e 1990. Rio de Janeiro: IBGE, 2019.

IBGE. Instituto Brasileiro de Geografia e Estatística. Pesquisa Mensal de Emprego. 2 ed. Rio de Janeiro: IBGE, 2007.

IBGE. Instituto Brasileiro de Geografia e Estatística. Sidra: sistema IBGE de recuperação automática. Rio de Janeiro: IBGE, 2011. 
IHA. International Hydropower Association. Sustainability assessment protocol. IHA, 2006.

LANG, M.. Alternativas ao Desenvolvimento. In: DILGER, G.; LANG, M.; PEREIRA FILHO, J.. Descolonizar o imaginário: debates sobre pós-extrativismo e alternativas ao desenvolvimento. São Paulo: Elefante, 2016. p.472.

LIMA, A. M. T.; MARQUES, E. E.; ERTZOGUE, M. H.; FERREIRA, D. T. A. M.; LIMA, J. D.. Os rios amazônicos convertidos em gigawatts: Participação social no processo de implantação de usinas hidrelétricas. Revista de Administração e Negócios da Amazônia, v.7, n.2, 2015.

LIMA, A. M. T.; BUSCHBACHER, R. J.; OLIVEIRA, N. M.; PINTO, M. D. S.; ALVES, E. O.; MARQUES, E. E.. Efeito pós-barragem nos municípios impactados por usinas hidrelétricas no estado do Tocantins/Brasil. Revista Ibero Americana de Ciências Ambientais, v.10, n.3, p.138-155, 2019.

LIMA, A. M. T.. Hidrelétricas no Rio Tocantins e efeitos pósbarragem: Compensação, desenvolvimento e governança local. Tese (Doutorado em Ciências do Ambiente) Universidade Federal do Tocantins, Palmas, 2020.

LITTLE, P. E.. Mega-development Projects in Amazonia: A geopolitical and socioenvironmental primer. Lima: Derechos, Ambiente y Recursos Naturales. 2014.

MALDANER, K.; LIMA, A. M.; AKAMA, A.; MARQUES, E. E.. A Avaliação Ambiental Integrada e os Cenários Socioeconômicos de Municípios Impactados Pelas Usinas Hidrelétricas Peixe Angical e São Salvador no Rio Tocantins. Revista Brasileira de Ciências Ambientais, n.52, p.119-134, 2019.

MALDANER, K. L. S.; AKAMA, A.. A Compensação Financeira e o Desenvolvimento de Municípios Impactados Por Hidrelétricas: Os Indicadores Sociais de Paranã e São Salvador do Tocantins. Revista Ibero-Americana de Ciências Ambientais, v.10, n.2, p.271-283, 2019. DOI: https://doi.org/10.6008/CBPC2179-6858.2019.002.0023

MENDONÇA, M. J. C.; MOTA, R. S.. Saúde e saneamento no Brasil. Rio de Janeiro: Ipea, 2005.

MOREIRA, S. V.. Análise documental como método e como técnica. In: JORGE, D.; BARROS, A.. Métodos e Técnicas de pesquisa em comunicação. São Paulo: Atlas, 2005.

OLIVEIRA, D. M.. Saneamento básico e desenvolvimento humano: um estudo de caso da Vila João Castelo no Município de Imperatriz/MA/Brasil. In: CONFERENCIA DE LA ASOCIACIÓN LATINOAMERICANA Y DEL CARIBE PARA EL DESARROLLO HUMANO Y EL ENFOQUE DE LAS CAPACIDADES, 5. Anais. Lima, 2014.

OLIVEIRA, J. M. M.. Estratégias separatistas e ordenamento territorial: a criação de Palmas na consolidação do estado do Tocantins. Tese (Doutorado em Geografia) - Universidade Federal de Uberlândia, Uberlândia, 2012.
OLIVEIRA, N. M.. Transição do Norte de Goiás ao território do estado do Tocantins. Revista Tocantinense de Geografia, Araguaína, v7, n.12, 2018.

PIMENTEL, M. T.; DIAS, R. R.; PEREIRA, E. Q.. Mapeamento das mudanças da cobertura e uso da terra entre os anos de 1984 e 2009 utilizando técnicas de sensoriamento remoto e geoprocessamento: estudo de caso do Município de Fátima - Estado do Tocantins. In: SIMPÓSIO BRASILEIRO DE SENSORIAMENTO REMOTO, 15. Anais. Curitiba: INPE, 2011. p.6810-6817.

PINHEIRO, M. F. B.. Problemas sociais e institucionais na implantação de hidrelétricas: seleção de casos recentes no Brasil e casos relevantes em outros países. Campinas, 2007.

SEPLAN-TO. Atlas do Tocantins: subsídios ao planejamento da gestão territorial. Palmas: SEPLAN, 2012.

SEPLAN-TO. Secretaria do Planejamento e Orçamento. Perfil Socioeconômico dos Municípios: Ipueiras. Diretoria de Pesquisa e Informações Econômicas Palmas - Tocantins. SEPLAN, 2017

SEPLAN-TO. Secretaria do Planejamento e Orçamento. Perfil Socioeconômico dos Municípios: Lajeado. Diretoria de Pesquisa e Informações Econômicas Palmas - Tocantins. SEPLAN, 2017.

SEPLAN-TO. Secretaria do Planejamento e Orçamento. Perfil Socioeconômico dos Municípios: Peixe. Diretoria de Pesquisa e Informações Econômicas Palmas - Tocantins. SEPLAN, 2017.

SEPLAN-TO. Secretaria do Planejamento e Orçamento. Planilhas. Diretoria de Pesquisa e Estatística. Palmas. SEPLAN, 2019.

SILVA, M. J.; JABER, M. T.; SATO, M. T.. Territórios em tensão: o mapeamento dos conflitos socioambientais do Estado de Mato Grosso - Brasil. Ambiente \& Sociedade, v.15, p.1-22, 2012

TEIXEIRA, J. C.; PUNGIRUM, C. M. E. M.. Análise da associação entre saneamento e saúde nos países da América Latina e do Caribe, empregando dados secundários do banco de dados da Organização Pan-Americana de Saúde - OPAS. Rev. Bras. Epidemiol., v.8, n.4, p.365-76, 2005.

THEMAG. Engenharia E Consultoria Ltda. UHE Lajeado. Relatório de Impacto sobre o Meio Ambiente. 1996.

TUNDISI, J. G.; MURA-TUNDISI, T. M.; SIDAGIS GALLI, C.. Eutrofização na América do Sul: causas, tecnologias de gerenciamento e controle. IIE, liega, IAP, lanas, ABC. 2006.

VAINER, C. B.; ARAÚJO, F. G. B.. Grandes projetos hidrelétricos e o desenvolvimento regional. Rio de Janeiro: Centro Ecumênico de Documentação e Informação, 1992.

VERA, I.; LANGLOIS, L.. Energy indicators for sustainable development. Energy, v.32, p.875-82, 2007.

A CBPC - Companhia Brasileira de Produção Científica (CNPJ: 11.221.422/0001-03) detém os direitos materiais desta publicação. Os direitos referem-se à publicação do trabalho em qualquer parte do mundo, incluindo os direitos às renovações, expansões e disseminações da contribuição, bem como outros direitos subsidiários. Todos os trabalhos publicados eletronicamente poderão posteriormente ser publicados em coletâneas impressas sob coordenação da Sustenere Publishing, da Companhia Brasileira de Produção Científica e seus parceiros autorizados. Os (as) autores (as) preservam os direitos autorais, mas não têm permissão para a publicação da contribuição em outro meio, impresso ou digital, em português ou em tradução. 